\title{
Low Versus High Prolactin Responders to Fenfluramine Challenge: Marker of Behavioral Differences in Adult Male Cynomolgus Macaques
}

M. Babette Botchin, D.V.M., Jay R. Kaplan, Ph.D., Stephen B. Manuck, Ph.D., and J. John Mann, M.D.

Prolactin response to acute administration of fenfluramine hydrochloride is considered an indirect assessment of "net" central serotonergic activity. This study compared behavioral characteristics of adult, male cynomolgus macaques (Macaca fascicularis) having "low" or "high" prolactin responses to fenfluramine challenge. The subjects were 75 animals housed in five-member social groups for 28 months. In month 23, prolactin responses to fenflu ramine challenge were evaluated. Observations of specific behaviors (aggressive, submissive, affiliative, and nonsocial) were made three times per week on animals in each social group. The dominance status of each animal within a social group was assessed at weekly intervals. Low prolactin responders had a significantly higher index of "overt" aggression (ratio of fights involving physical contact and chasing or lunging/all forms of aggressive behavior) compared to high prolactin responders ( $\mathrm{p}<$ .03). There were no differences in the dominance status of low and high responders $(\mathrm{p}=.34)$. Furthermore, low responders were more socially withdrawn than high responders, as they spent significantly more time alone (passive or neutral state; $\mathrm{p}<.03$ ) and less time in passive body contact with other animals than high responders $(\mathrm{p}<.05)$. These data support the hypothesis that reduced central serotonergic activity in nonhuman primates is associated with a high level of overt aggression and a low level of positive social interaction. [Neuropsychopharmacology 9:93-99, 1993]
KEY WORDS: Aggression; Serotonin; Fenfluramine; Prolactin; Cynomolgus macaques; Social behavior

Studies in human beings demonstrate a relationship between low serotonergic activity and the propensity for impulsive aggression among violent criminal offend-

From the Comparative Medical Clinical Research Center, Bowman Gray School of Medicine of Wake Forest University (MBB, JRK), Winston-Salem, North Carolina; Behavioral Physiology Laboratory, Department of Psychology (SBM), and the Department of Psychiatry, Western Psychiatric Institute and Clinic (JJM), University of Pittsburgh, Pittsburgh, Pennsylvania.

Address correspondence to: M. Babette Botchin, D.V.M., Comparative Medicine Clinical Research Center, Bowman Gray School of Medicine, Medical Center Boulevard, Winston-Salem, NC 271571040

Received October 15, 1992; revised February 16, 1993; accepted february 22, 1993. ers (Linnoila et al. 1983; Lidberg et al. 1985), arsonists (Virkkunen et al. 1987), individuals with aggressive personality traits (Brown and Goodwin 1986), and normal volunteers (Roy et al. 1988). These studies used cerebrospinal fluid (CSF)-5-hydroxyindoleacetic acid (5-HIAA) concentration as the index of central serotonergic activity. Low serotonergic activity is also associated with selfdirected aggression, based on evidence from studies of suicide attempters and suicide victims (Asberg et al. 1987; Mann et ai. 1989). Presynaptic indices such as serotonin (5-HT) transporter binding were reduced, and postsynaptic indices such as cortical $5-\mathrm{HT}_{2}$ binding were shown to be increased in suicide victims (Stanley et al. 1982; Stanley and Mann 1983; Arango et al. 1990).

Cocarro et al. (1989) employed the prolactin response to challenge with fenfluramine (an indirect 
serotonergic agonist) to assess "net" pre- and postsynaptic serotonergic activity in patients with either major affective disorder or personality disorder. They observed that the prolactin response was reduced in both groups of patients, particularly those who had attempted suicide, compared to normal controls. Reduced prolactin responses were associated with impulsive aggression and suicide attempts in panic disorder patients and with suicide attempts in major affective disorder patients and did not correlate with the severity of depressive or anxiety states in either group. These results suggest that "net" serotonergic activity, as measured by prolactin response to fenfluramine challenge, was reduced in association with impulsive aggression in nondepressed patients.

It is not known what association may exist between prolactin response to fenfluramine challenge and aggressive or other behaviors in individuals without a history of psychiatric disorders or drug abuse. Using grouphoused cynomolgus macaques to model human social behavior, this study was designed to test the hypothesis that differences in central serotonergic activity, measured by prolactin response to fenfluramine challenge, are associated with corresponding differences in the aggressive, affiliative, or nonsocial behaviors of healthy cynomolgus macaques.

\section{METHODS}

\section{Subjects}

The subjects were 75 adult male cynomolgus monkeys that were part of an experiment evaluating the effects of diet and social stress on progression of coronary artery atherosclerosis. All animals consumed the same moderately atherogenic experimental diet, which consisted of: cholesterol, $0.253 \mathrm{mg} / \mathrm{Cal}$; protein, $17.9 \%$ of calories; fat, $43.3 \%$ of calories; and carbohydrate, $38.8 \%$ of calories. The animals were housed in 15 five-member social groups for 28 months. The social stress manipulation involved periodic redistribution of members into new social groups. There were three study conditions: 1) a control (no-stress) condition that remained stable in social composition; 2) an early-stress condition, in which groups were reorganized monthly during only the first half of the experiment; and 3) a late-stress condition, in which groups were reorganized during only the last half of the study. Three animals died of causes unrelated to the manipulation, leaving 72 animals for use in all analyses.

\section{Blood Sampling and Fenfluramine Challenge}

On the first day of the 23rd month of the study, the social group membership (late-stress condition only) was reorganized. On day 14, sham injections were given
(08:00 to 10:00 hours) and blood samples were taken (09:00 to 11:00 hours) from all animals in the study using the following procedures. All animals in a social group were placed in a squeeze cage and given sham intramuscular (IM) injections of sterile saline. The animals were then returned to the group home cage. One hour later, the group was returned to the squeeze cage and anesthetized with ketamine hydrochloride $(10 \mathrm{mg} / \mathrm{kg}$, IM). Blood samples were collected by venipuncture 10 to 20 minutes after the animals were anesthetized. The samples were transferred into tubes containing ethylenediaminetetraacetic acid (EDTA) and frozen at $-20^{\circ} \mathrm{C}$ for later determination of baseline plasma-prolactin levels.

On day 28, between 08:00-10:00 hours, the animals were given $4 \mathrm{mg} / \mathrm{kg}$ fenfluramine hydrochloride intramuscularly using the same procedures described for the sham injection. One hour later, blood samples were again collected (as described above) and frozen at $-20^{\circ} \mathrm{C}$. The animals were fasted for 12 hours prior to the sham and challenge procedures. Plasma-prolactin levels were determined by radioimmunoassay (rabbit anti-human prolactin serum purchased from Ian Worsley, Winnipeg, Manitoba, Canada). The lower limit of detection for this assay is $1.0 \mathrm{ng} / \mathrm{ml}$.

\section{Behavioral Observations and Quantification}

Specific behavioral events categorized as aggressive, submissive, and affiliative were recorded from each social group, three times per week, in 30 minute sessions using ad libitum and scan sampling techniques (Altman 1974). These behavioral events subsume those motor patterns displayed most frequently by cynomolgus monkeys living in small social groups (Table 1; Kaplan et al. 1982). Behavioral events that occurred nearly instantaneously (such as fights) were measured in fre quency per hour per monkey. Behavioral events that occurred over a period of time ("states") were recorded as the percentage of time that the animal demonstrated the behavior (Kaplan et al. 1993).

Behaviors categorized as aggressive or submissive are composed of component motor patterns that differ in relative intensity. Therefore, aggressive and submissive behavioral events were both broken into categories reflecting rates of performance of high-intensity actions (such as bites) as well as overall frequencies (Table 1). Additionally, total frequencies of aggressive events are biased in that the rates of intense and mild aggression tend to be highly correlated with overall rates of aggression ( $r$ 's $>0.60, n=75, p<.001)$. The overall rates of aggression, in turn, are influenced by environmental factors, including the behavior of surrounding animals. Therefore, an "overt" aggression index (ratio of intense forms of aggression/all forms of aggression) was used to reflect the relative mix of behaviors employed by animals when they were aggressive in fights, 
Table 1. Behavioral Characterization of Adult Male Cynomolgus Macaques

\begin{tabular}{lll}
\hline Category & \multicolumn{1}{c}{ Behavioral Event } & Unit of Measurement* \\
\hline $\begin{array}{c}\text { Aggression } \\
\text { Intense }\end{array}$ & $\begin{array}{c}\text { Hit, bite, grapple, chase, } \\
\text { charge, lunge } \\
\text { Displaces, stare threat, } \\
\text { open mouth threat }\end{array}$ & Frequency/hr \\
$\begin{array}{c}\text { Mubmission } \\
\text { Intense }\end{array}$ & $\begin{array}{c}\text { Flee, crouch, scream } \\
\text { Mild }\end{array}$ & $\begin{array}{l}\text { Jump, turn away, grimace, } \\
\text { is displaced, presents }\end{array}$ \\
$\begin{array}{c}\text { Affiliative } \\
\text { Social }\end{array}$ & $\begin{array}{c}\text { Groom, being groomed, } \\
\text { passive body contact } \\
\text { Alone (passive; neutral } \\
\text { state; }>6 \text { inches from } \\
\text { body contact) }\end{array}$ & $\begin{array}{c}\text { Frequency } / \mathrm{hr} \\
\text { Frequency/hr }\end{array}$ \\
\hline
\end{tabular}

* All behavior except percent of time alone and percent of time in body contact were logarithmically transformed for the repeated-measures ANCOVA procedure.

regardless of the overall rates of aggression. This index assesses individual overt aggression free of environmental or idiosyncratic influences (correlation of overt index with total aggression $=r<0.25, n=75$, NS). A similar behavioral index has been used by other investigators (Mehlman 1992). The ratio of intensely submissive behavior/total submission was also calculated and evaluated.

The occurrence of each behavior was recorded using an electronic data collection device (Tandy Co., Radio Shack TRS 80). Observations were made in the morning (09:00 to 11:00 hours) and in the afternoon (14:00 to 16:00 hours) and were balanced for time of day of sampling. The data reported here represent the mean occurrence of the behaviors over the first and second halves of the study (i.e., months 1 to 14 and 15 to 28 ).

\section{Dominance Status (Social Rank)}

The outcome of agonistic encounters was used to determine the dominance status or rank of the individual animals within each social group (Sade 1967; Kaplan et al. 1982). Matrices were constructed that delineated the frequency of fights among all possible pairs of monkeys within each social group. The animal in each group that defeated all others, as evidenced by the elicitation of submissive gestures, was designated the first-ranking monkey. The monkey that defeated all but the firstranking monkey was designated as the second ranking and so forth. The dominance hierarchy was thus determined for each social group and was reassessed at 4-week intervals throughout the study period. Because individual ranks determined at the time of the challenge were highly and significantly correlated with individual social rank averaged over the entire experi- ment $(r=0.60, n=75, p<.001)$, the latter was used in Chi-square analysis of the distribution of social rank among prolactin responders.

\section{Statistical Analysis}

Logarithmic transformation of the behavioral indices (as indicated in Table 1) and prolactin concentration (baseline and postchallenge) were used to reduce skewness and equalize group variances. The data were analyzed using the BMDP software procedure for analysis of covariance (ANCOVA) with repeated measures. Chisquare analysis was used to assess the distribution of prolactin responders within experimental groups and social rank among prolactin responders.

\section{RESULTS}

\section{Characteristics of Prolactin Response to Fenfluramine}

The distribution of prolactin response to fenfluramine was bimodal (Fig. 1); therefore, the subjects were grouped as "low responders" and "high responders" for analysis ( $n=36$ in both groups). Chi-square analysis indicated that high and low prolactin responders were distributed equivalently across the three experimental conditions (no stress, early stress, late stress; $\left.\chi^{2}=3.14, d f=2, p=.21\right)$. Baseline prolactin concentrations were low (mean $\pm \mathrm{SD}=1.8 \mathrm{ng} / \mathrm{ml} \pm 1.2$ ) but correlated significantly with fenfluramine response ( $r=0.43, n=72, p<.001)$; therefore, baseline prolactin concentration was used as a covariate in all repeatedmeasures analyses comparing the behavior of low and high prolactin groups. 


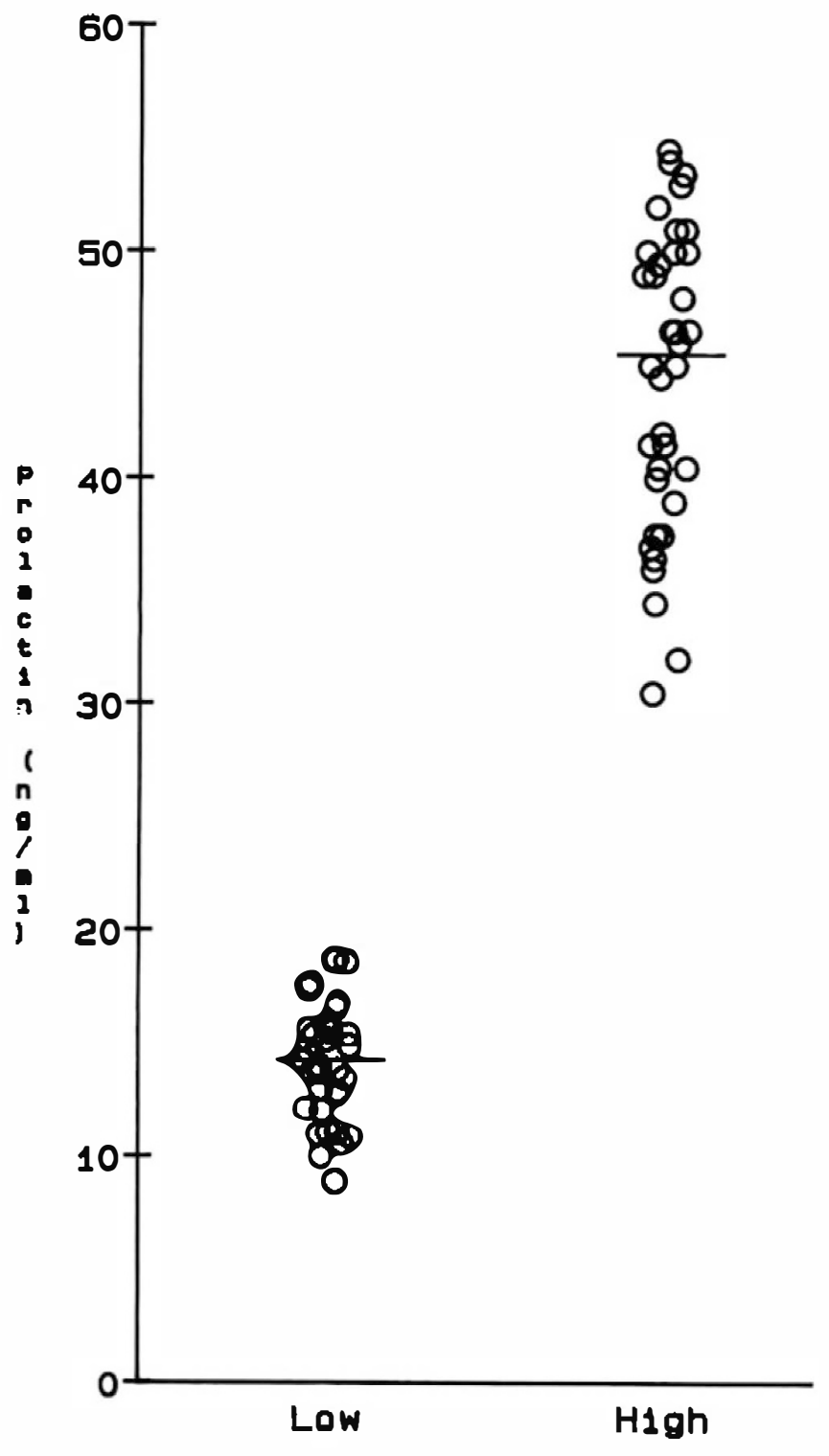

Prolactin Response

Figure 1. Prolactin responses to fenfluramine challenge were distributed bimodally. The animals were grouped into "low" $(n=36)$ and "high" $(n=36)$ responders for ANCOVA. The horizontal bar represents the mean prolactin response.

\section{Social Behavior, Social Rank, and Prolactin Response}

To determine whether low responders differed from high responders in aggression, submission, and affiliation, the behavioral data were analyzed using a $2 \times$ $3 \times 2$ repeated-measures ANCOVA. There were two between-subjects factors (Prolactin Response low, high and Experimental Condition no stress, early stress, late stress) and one within-subjects factor (Time Period months 1-14, 15-28).
There were no significant main effects (Prolactin Response or Experimental Condition) on the absolute frequencies of total or intense aggression (all $F^{\prime}$ s NS), although significant Prolactin Response $\times$ Experimental Condition interactions for both variables (total aggression: $F[2,65]=3.26, p<.05$; intense aggression: $F[2,65]=3.19, p<.05)$ were observed. With respect to these interactions, however, pairwise comparisons among means (Bonferroni test) revealed no significant difference between low and high prolactin responders within or between any of the three experimental groups in the frequencies of either total or intense aggression (all F's NS).

Results of the analysis involving the overt aggression index are shown in Figure 2. During agonistic encounters, low responders displayed a significantly higher degree of overt aggression than high responders $(F[1,65]=4.93, p<.03)$. No other significant main effects or interactions were observed.

Repeated-measures ANCOVA of the frequencies of total and intense submissive behavior (displayed when animals lose agonistic encounters) revealed no significant main effects for Prolactin Response or Experimental Condition (all F's NS). A significant Prolactin Response $\times$ Experimental Condition interaction was observed in the frequencies of both total $(F[2,65]=4.02$, $p<.03)$ and intense $(F[2,65]=4.07, p<.03)$ submissive behavior. However, as with the analysis of aggression, the Bonferroni test revealed no significant differences between low and high prolactin responders within any Experimental Condition (all F's NS). A significant Experimental Condition $\times$ Time interaction (Total: $F[2,66]=$ $4.64, p<.02$; Intense: $F[2,66]=4.06, p<.03$ ) was also observed. The frequency of submissive behavior was higher in the last half (months 15 to 28) compared to the first half of the study (months 1 to 14) only in the late-stress group. Finally, there were no significant main effects or interactions in the ratio of the frequencies of intense submissive acts/total submissive acts.

The results of the analyses of affiliative and nonsocial behavior are shown in Figure 3. Low responders spent significantly more time alone $(F[1,65]=5.05, p<$ .03 ) and significantly less time in body contact with others $(F[1,65]=4.33, p<.05)$ compared to high responders. In addition to the main effect for Prolactin Response, a significant Experimental Condition $\times$ Time interaction was found in percent of time spent in body contact $(F[2,66]=6.76, p<.01)$. The percent of time spent in body contact increased in the late-stress groups from the first to the second half of the study, whereas the no-stress and early-stress groups showed a decrease in this parameter between the two periods of the experiment. Additionally, there was a significant main effect of Time $(F[1,66]=9.79, p<.01)$ for percent of time alone, reflecting the fact that all animals spentless time alone in the second half of the study. 
Overt Aggression ( \pm SE)

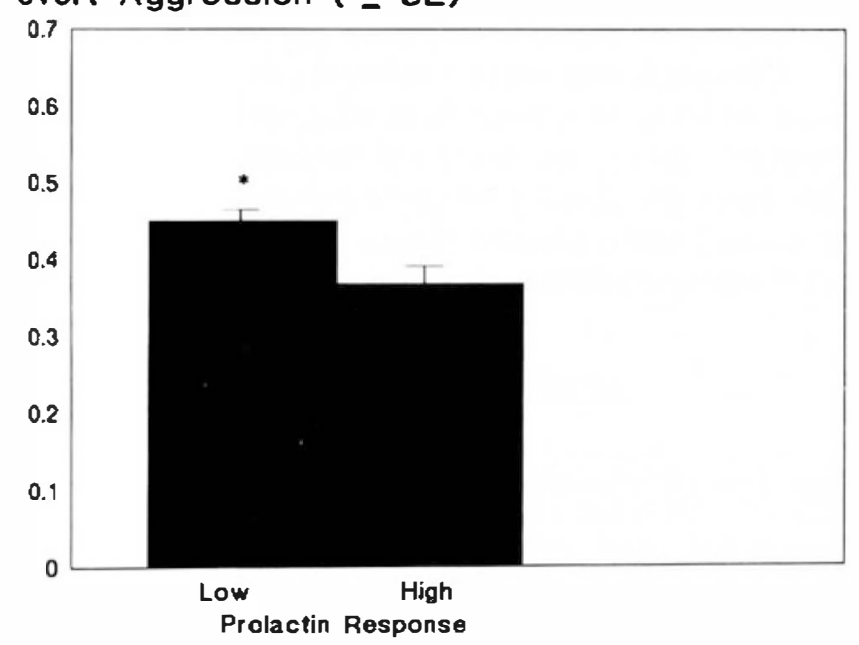

Figure 2. Mean incidence of "overt" aggression, which is an index defined as the ratio of intense forms (bite, grab, chase)/all forms, among "low" $(n=36)$ versus "high" $(n=$ 36) responders. Results are presented from the untransformed data. ${ }^{\star} F[1,65]=4.93, p<.03$ after logarithmic transformation of behavior and prolactin concentration; covariate is baseline prolactin concentration.

Low responders did not differ from high responders in rate or percent of time grooming or being groomed.

Furthermore, no differences in social status (rank) were found between the low and high prolactin responders $\left(\chi^{2}=0.94, d f=1, p=.33\right)$.

\section{DISCUSSION}

The prolactin response to fenfluramine challenge was used as a measure of "net" central serotonergic responsivity to evaluate the relationship between social behavior and 5-HT in a random population of monkeys. The results demonstrate that animals had either high orlow prolactin responses to fenfluramine, suggesting that serotonergic activity is bimodally distributed. Importantly, animals having a low response to fenfluramine challenge (indicative of low central serotonergic responsivity) displayed significantly higher "overt" aggressivity and social withdrawal (more time alone, less time in physical contact with others) than did animals with high prolactin responses. Behavioral differences between the high and low responders were not influenced by dominance status. Social stress induced by recent (late stress) or previous (early stress) reorganization of group membership on a monthly basis apparently had no effect on the prolactin response to fenfluramine challenge.

The findings of higher levels of overt aggression in low compared to high prolactin responders is con-

\section{\% Time ( $\pm S E)$}

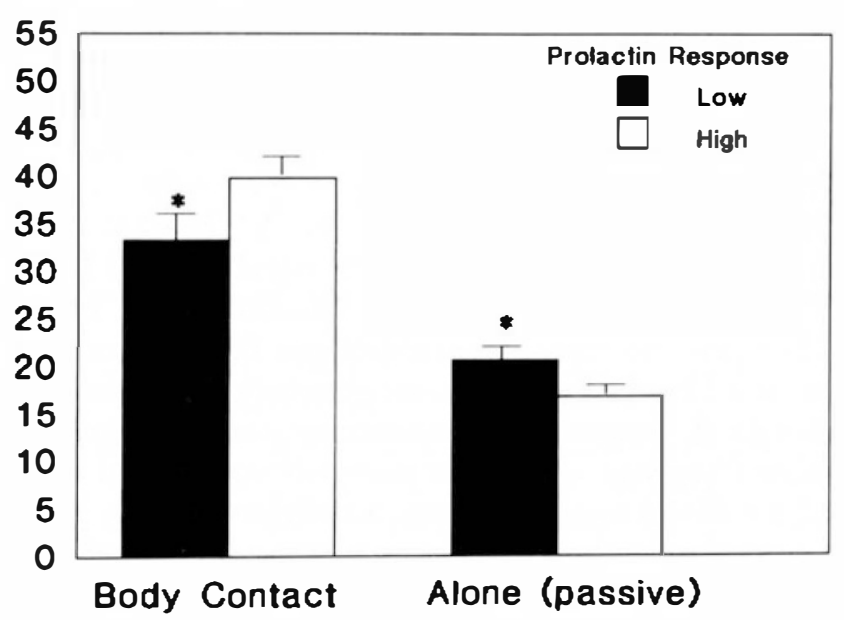

Figure 3. Differences in affiliative (social) behavior (measured as mean percent of time spent in body contact or alone) among "low" $(n=36)$ and "high" $(n=36)$ responders. * Percent of time body contact: $F[1,65]=4.33 ; p<.05$; percent of time alone: $F[1,65]=5.05 ; p<.05$; baseline prolactin concentration (logarithmic transformation) was covariate in both analyses.

sistent with the observation that high aggressivity (also measured as the ratio of aggressive behavior involving physical contact/all aggressive behavior) is inversely correlated with CSF concentrations of 5-HIAA in adolescent male rhesus monkeys (Mehlman et al. 1992). Both of these studies suggest that this index of aggression is associated with reduced serotonergic activity.

In vervet monkeys, chronic fenfluramine treatment reduced 5-HIAA concentrations in CSF and resulted in increased aggressive behavior and decreased affiliative behavior in adult males (Raleigh et al. 1991). In freeranging male rhesus monkeys, Higley et al. (1992) found a significant inverse correlation between CSF-5-HIAA concentrations and ratings of aggression. These two species are members of different tribes in the Cercopithecinae subfamily and are characterized by distinctly different social organizations and behavioral features (Kaplan 1987), yet the association between reduced serotonergic activity and high aggressivity is remarkably similar.

Affiliative behaviors also appear to be influenced by serotonergic activity. In the current study, low responders were more socially withdrawn compared to high responders. The low responders spent more time alone, apparently inattentive to the social environment, and less time in a positive, affiliative state (passive body contact). In vervet monkeys, depletion of 5 -HT by chronic fenfluramine administration increased aggressive behavior and significantly decreased affiliative behaviors such as proximity to other animals (Raleigh et al. 1991). These findings suggest that, across species, serotonergic activity may directly influence affiliative 
behavior, independent of any concomitant effects on aggression.

The prolactin response to fenfluramine differs from other indices of serotonergic activity for two reasons. Fenfluramine stimulates prolactin release through indirect activation of postsynaptic receptors by the presynaptic release of endogenous $5-\mathrm{HT}$, as well as through inhibition of 5-HT reuptake (Garattini et al. 1979; Rowland and Carlton 1986; Quattrone et al. 1982). Therefore, net pre- and postsynaptic function can be assessed in the hypothalamic-pituitary axis. The current study suggests that prolactin response to fenfluramine challenge should be positively correlated with CSF-5-HIAA concentrations, which has recently been demonstrated in human beings (Mann et al. 1992). Therefore, this response would provide an indirect measure of central serotonergic activity.

The specific releasing factor through which 5-HT stimulates prolactin release is unknown. Previous studies have shown that neither thyrotropin-releasing factor (Cocarro et al. 1988) nor dopaminergic mechanisms (Pilotte and Porter 1981; Kaji et al. 1985) are involved. However, in the current study, baseline prolactin concentration correlated significantly with prolactin response to fenfluramine challenge, which may reflect resting serotonergic tone, dopaminergic mechanisms (causing a direct inhibitory action on pituitary lactotroph cells [Cronin 1982]), or lactotroph responsivity. Although we cannot determine whether functional alterations at the level of the lactotroph are involved in this response, previous studies have not consistently found reduced prolactin responses to thyrotropin-releasing hormone in depressed patients compared to controls (Cocarro et al. 1988). Because our results were independent of basal prolactin levels, they are probably due to serotonergic effects.

In conclusion, in adult male cynomolgus macaques, a lower prolactin response to fenfluramine challenge was associated with relatively high levels of overt aggressivity and social withdrawal. Although low responders had higher levels of overt aggression, they did not differ in dominance status. However, the ability to defeat others in agonistic encounters is not necessarily related to the levels of aggression displayed (Manuck et al. 1983). Insofar as prolactin response to fenfluramine challenge assesses "net" serotonergic activity, these data support related findings in human and nonhuman primateslinking reduced serotonergic activity and aggression. The bimodal distribution of prolactin responses to fenfluramine observed is striking and has not been described previously in clinical studies using fenfluramine. This finding suggests the existence of two distinct populations of monkeys that differ in "net" central serotonergic activity; such a distinction implies selection pressure favoring disparate adaptive strate- gies regarding aggressive, antisocial, or asocial behavior.

This study was the first to use the fenfluramine challenge technique, a clinical tool, in nonhuman primates. Further studies are required to determine whether dopaminergic activity or specific characteristics of the pituitary lactotroph cells also influence the response to fenfluramine challenge in cynomolgus macaques.

\section{ACKNOWLEDGMENTS}

This research was supported by Public Health Service Grants HL40962, HL14164, and MH46745. We thank Dr. MichaelJ. Raleigh for expert advice and assistance in the design of the fenfluramine challenge procedure.

\section{REFERENCES}

Altmann J (1974): Observational study of behavior: Sampling methods. Behaviour 49:227-267

Arango V, Ernsberger P, Marzuk PM, Chen J, TierneyH, Stanley M, Reis DJ, Mann JJ (1990): Autoradiographic demonstration of increased $5-\mathrm{HT}_{2}$ and $\beta$-adrenergic receptor binding sites in the brain of suicide victims. Arch Gen Psychiatry 47:1038-1047

Asberg M, Schalling D, Traksman-Bendz L, Wagner A (1987): Psychobiology of suicide, impulsivity, and related phenomena. In Meltzer HY (ed) Psychopharmacology: Third Generation of Progress. New York, Raven Press, pp 655688

Brown GL, Goodwin FK (1986): Human aggression and suicide. Suicide Life Threat Behav 16:141-162

Coccaro EF, Siever LJ, Klar HM, Maurer G, Cochrane K, Cooper TB, Mohs RC, Davis KL (1989): Serotonergic studies in patients with affective and personality disorders. Arch Gen Psychiatry 46:587-599

Coccaro EF, Siever LJ, Kourides IA, Adan FA, Campbell G, Davis KL (1988): Central serotonergic stimulation by fenfluramine challenge does not affect plasma thyrotropin-stimulating hormone levels in man. Neuroendocrinology 47:273-276

Cronin MJ (1982): The role and direct measurement of the dopamine receptor(s) of the anterior pituitary. In MacLeod RM, Muller EE (eds) Neuroendocrine Perspectives. Amsterdam, Elsevier/North-Holland, Vol 1; pp 167-208

Garattini S, Caccia S, Mennini T, Samanin R, Consolo S, Ladinsky $H$ (1979): Biochemical pharmacology of the anorectic drug fenfluramine: A review. Curr Med Res Opin 6(Suppl 1):15-27

Higley JD, Mehlman PT, Taub DM, Higley SB, Suomi SJ, Linnoila M, Vickers JH (1992): Cerebrospinal fluid monoamine and adrenal correlates of aggression in free-ranging rhesus monkeys. Arch Gen Psychiatry 49:436-441

Kaji H, Chihara K, Abe H, Kita T, Kashio Y, Okimura Y, Fujita $T$ (1985): Effect of passive immunization with antisera to vasoactive intestinal polypeptide and peptide histidine isoleucine amide on 5-hydroxy-L-tryptophan-induced prolactin release in rats. Endocrinology 117:1914-1919 
Kaplan JR (1987): Dominance and affiliation in the Cercopithecini and Papionini: A comparative examination. In Zucker EL (ed) Comparative Behavior of African Monkeys. New York, Alan R. Liss, pp 127-150

Kaplan JR, Manuck SB, Clarkson TB, Lusso FM, Taub DM (1982): Social status, environment and atherosclerosis in cynomolgus monkeys. Arteriosclerosis 2:359-368

Kaplan JR, Manuck SB, Adams MR, Williams JK, Register TC, Clarkson TB (1993): Plaque changes and arterial enlargement in atherosclerotic monkeys after manipulation of diet and social environment. Arterioscler Thromb 13: 254-263

Lidberg L, Tuck JR, Asberg M, Scalia-Tomba GP, Bertilsson L (1985): Homicide, suicide and CSF 5-HIAA. Acta Psychiatr Scand 71:230-236

Linnoila M, Virkkunen M, Scheinen M, Nuutila A, Rimon R, Goodwin FK (1983): Low cerebrospinal fluid 5-hydroxyindoleacetic acid concentration differentiates impulsive from non-impulsive violent behavior. Life Sci 33:26092614

Mann JJ, Arango V, Marzuk PM, Reis DJ (1989): Evidence for the 5-HThypothesis of suicide: A review of post-mortem studies. Br J Psychiatry 155(Suppl 8):7-14

Mann JJ, McBride PA, Brown RP, Linnoila M, Leon AC, DeMeo M, Mieczkowski T, Myers JE, Stanley M (1992): Relationship between central and peripheral serotonin indexes in depressed and suicidal psychiatric patients. Arch Gen Psychiatry 49:442-446

Manuck SB, Kaplan JR, Clarkson TB (1983): Behaviorally induced heart rate reactivity and atherosclerosis in cynomolgus monkeys. Psychosom Med 45:95-108
Mehlman PT, Higley JD, Faucher I, Corr J, Taub DM, Dodson A, Lilly A, Linnoila M, Suomi S (1992): CNS 5-HIAA and aggression in free-ranging adolescent rhesus males. Am J Primatol 27:46

Pilotte NS, Porter JC (1981): Dopamine in hypophyseal portal plasma and prolactin in systemic plasma of rats treated with 5-hydroxytryptamine. Endocrinology 108:2137-2141

Quattrone A, Schettini G, DiRenzo G, Amoroso S, Annuziato L (1982): An in vivo useful tool to evaluate the activity of serotonin uptake inhibitors: prevention by chlorimipramine of the prolactin-releasing action of $d$-fenfluramine. Adv Biochem Psychopharmacol 31:229-234

Raleigh MJ, McGuire MT, Brammer GL, Pollack DB, Yuwiler A (1991): Serotonergic mechanisms promote dominance acquisition in adult male vervet monkeys. Brain Res 559:181-190

Rowland NE, Carlton J (1986): Neurobiology of an anorectic drug: Fenfluramine. Prog Neurobiol 27:13-62

Roy A, Adinoff B, Linnoila M (1988): Acting out hostility in normal volunteers: Negative correlations with 5-HIAA in cerebrospinal fluid. Psychiatry Res 24:187-194

Stanley M, Mann JJ (1983): Increased serotonin-2 binding sites in frontal cortex of suicide victims. Lancet I:214-216

Stanley M, Virgilio J, Gershon S (1982): Tritiated imipramine binding sites are decreased in the frontal cortex of suicides. Science 216:1337-1339

Virkkunen M, Nuutila A, Goodwin FK, Linnoila M (1987): Cerebrospinal fluid metabolite levels in male arsonists. Arch Gen Psychiatry 44:241-247 